\title{
Building Farming Resilience to Climate Change: Upland Crop Production in Northwest Cambodia ${ }^{\dagger}$
}

\author{
Van Touch 1,*, De Li Liu ${ }^{2}$, Robert John Martin ${ }^{1}$, Jeannette Fiona Scott ${ }^{3}$, Annette Cowie ${ }^{4}$ and \\ Daniel K. Y. Tan ${ }^{1}$ \\ 1 Faculty of Science, School of Life and Environmental Sciences, Sydney Institute of Agriculture, \\ The University of Sydney, Eveleigh, NSW 2015, Australia; bob.martin@sydney.edu.au (R.J.M.); \\ daniel.tan@sydney.edu.au (D.K.Y.T.) \\ 2 NSW Department of Primary Industries, Wagga Wagga, NSW 2650, Australia; de.li.liu@dpi.nsw.gov.au \\ 3 NSW Department of Primary Industries, Tamworth, NSW 2340, Australia; fiona.scott@dpi.nsw.gov.au \\ 4 NSW Department of Primary Industries, Armidale 2351, Australia; annette.cowie@dpi.nsw.gov.au \\ * Correspondence: van.touch@sydney.edu.au or van.touch84@gmail.com \\ + Presented at the Third International Tropical Agriculture Conference (TROPAG 2019), Brisbane, Australia, \\ 11-13 November 2019.
}

Published: 7 April 2020

\begin{abstract}
Production of upland crops such as maize, cassava, soybean, mungbean, peanut and sesame contribute importantly to Cambodia's economy and food security, especially for those who live in the upland areas found in almost every province of Cambodia. The upland farmers are highly vulnerable to climate variability and climate change due to low adaptive capacity and high dependence on rainfed crop production for their livelihoods. This study involved in-depth review of literature, conducting on-farm experiments, downscaling climate projections from the coupled Model Intercomparison Project Phase 5 (CMIP5) General Circulation Models (GCMs), running Agricultural Production Systems sIMulator (APSIM) simulations and farmer consultation to define climate impacts and explore adaptation options that could build resilience to the existing and projected climate change scenarios for upland cropping farmers in Northwest Cambodia. Insufficient water and nutrient depletion were the main production risks and yield limiting factors. On-farm adaptation options such as modifying sowing windows, including legumes in crop rotations and additional fertiliser application are likely to substantially minimise risks from climatic impacts, and increase and sustain returns. Wider adoption of conservation agriculture practicesincluding reduced tillage and crop residue retention, that enhance soil structure and soil water holding capacity and reduce soil erosion, should enhance productivity and incomes, while making the farming systems more resilient to the existing and projected climate variability and climate change, and other production stressors.
\end{abstract}

Keywords: Cambodia; upland crop production; climate change adaptation; climate variability; APSIM

Author Contributions: For research articles with several authors, a short paragraph specifying their individual contributions must be provided.

Funding: This research is funded by the Australian Centre for International Agricultural Research (ACIAR).

Acknowledgments: The authors are grateful to the Australian Centre for International Agricultural Research(ACIAR) for funding this research project. Many thanks to all staff from the Agronomy and Soil Science Department and the International Office of The University of New England; especially, Ms. Roslyn Mortimer, Dr. Paul Kristiansen, Prof. Graeme Blair, Ms. Shirley Fraser, Mr. Chris Cooper, Mr. Frank Leayr and Ms. Alex Pearce for their support and contributions during my research. Big thanks also to the University of Battambang's undergraduates and staff who assisted in the data gathering. 
Conflicts of Interest: The authors declare no conflict of interest. article distributed under the terms and conditions of the Creative Commons Attribution (CC BY) license (http://creativecommons.org/licenses/by/4.0/). 